Alicja Krzymowska-Kostrowicka

\title{
ASSESSMENT OF THERAPEUTICAL VALUES OF NATURAL ENVIRONMENT FOR RECREATIONAL NEEDS. A CASE STUDY OF WARSAW ENVIRONS
}

Among elements which co-create natural environment of special importance for summer recreation are climatic conditions, relief, occurrence of open waters and vegetation. All of them constitute specific ecological conditions which exert a positive or negative influence on health and comfort of the resting persons.

The current research on recreational usefulness of natural environment, from the point of view of its impact on the process of resting itself, focuses chiefly on bioclimatological assessment from the viewpoint of climatology and related to variables of sun radiation, temperature, humidity, movement of air masses etc. However, chemical and biological variables that co-create local bioclimate were not subject to a more intensive research.

This paper is an attempt at integral approach to the conditions of rest in natural environment from the point of view of their influence on health and comfort of persons taking a rest.

A principal spatial unit taken as an object of investigation was a concrete ecosystem distinguished on the basis of character and pattern of vegetation. The mean variables were defined for ecosystems of every type occurring in the Warsaw suburban zone on the basis of analysis of vegetation pattern. The variables depict: (a) health values of the particular ecological units, and (b) aesthetic-emotional attractiveness of these units of both close and distant range.

While evaluating somatic and psycho-stimulating impact of the recreational environment two groups of incentives are of special importance: somatic and emotional. The former influence human organism directly through various receptors of the body; the latter regulate psychical condition of a recreating? person through stimulating or keeping down the sympathetic or parasympathetic nervous system.

In assessing the character and directions of action of somatic stimuli, the following variables were taken into account:

- a daily supply of the recreational layer of the air with radial energy (insolation of a layer of $50-200 \mathrm{~cm}$ above the ground) in summer; 
- relative humidity of a recreational layer reduced to standard weather conditions according to $S$ mith (wind velocity $-0.5-1 \mathrm{~m} / \mathrm{sec}$., summer temperature $-18^{\circ}-22^{\circ} \mathrm{C}$, cloudiness $-10-30$ per cent of the skies covered);

- airing of the system during the day in the recreational layer in summer in standard weather conditions;

- filtration features of the system, inlcuding the range of possibilities of acoustic waves suppression, catching and re-absorption of dust and gas contaminants;

- average intensity of the natural nuclear radiation of the ground;

- oxygenation of a recreational layer at various hours of the day of vegetation season in standard weather conditions;

- amount of ozone in the recreational layer (in conditions as above);

- ionization of the air of the recreational layer, i.e. the relationship between heavy and light iones and the positive and negative ones (the so-called index of polarity);

- biochemical and pharmacological properties of aeorosoles emitted to the recreational layer of the air by vegetation and soil;

- amount of aeroplancton in the air of the recreational layer, both organic (pollen, tiny organisms etc.) and non-organic;

- occurrence in the ecosystem of animals being a threat to health or limiting the possibility of a rest.

As a basis for assessment of the emotional type, the following features of ecosystems were assumed:

- colour structure of the system in various periods of the summer season;

- sound (acoustic) structure of the system in various periods of the summer season;

- general visual attractiveness of a close range that values objects and phenomena discernible in detail (varying from $1 \mathrm{~m}$ to $50 \mathrm{~m}$ );

- general visual attractiveness of a distant range (of landscape) that values a "landscape scene" as a whole, its areal richness, harmony etc.

Information on the above-mentioned variables was gathered either directly in the area or adequately adapted from the rich literature related in particular to chemical and biological impact of recreational zones on bioclimatic conditions of the particular types of ecosystems.

\section{CONCLUSIONS}

1. The research has revealed that the ecosystem of every type modifies general climatic conditions in its peculiar way only and creates its specific recreational bioclimate with definite health properties.

2. As a result of cooperation of climatic elements with physico-chemical elements characteristic of the particular vegetation types (level and character of ioniza- 


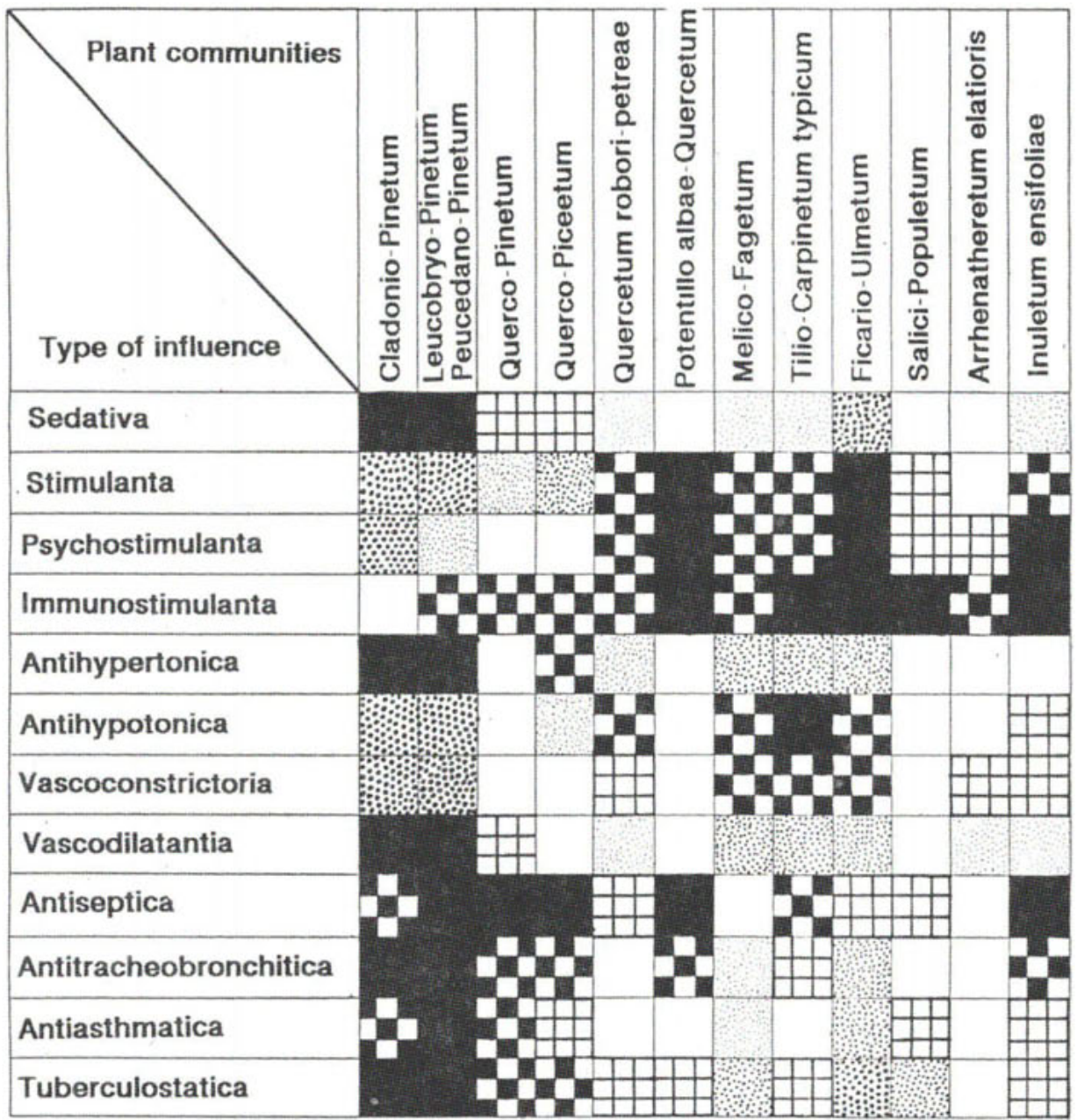

\begin{tabular}{|c|c|c|c|c|c|c|c|c|c|c|c|c|c|}
\hline \multirow{3}{*}{ 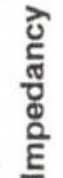 } & plant pollens & $\mathrm{m}$ & $\mathrm{m}$ & $\mathrm{m} / \mathrm{d}$ & $\mathrm{m} / \mathrm{d}$ & $\mathrm{m} / \mathrm{d}$ & d & $\mathrm{m}$ & d & $d / b d$ & bd & bd & d \\
\hline & insects & m & $\mathrm{m}$ & $\mathrm{m} / \mathrm{d}$ & $\mathrm{m} / \mathrm{d}$ & d & m & $\mathrm{m} / \mathrm{d}$ & $d / b d$ & $\mathrm{~d} / \mathrm{bd}$ & $d / b d$ & $\mathrm{~d} / \mathrm{bd}$ & $\mathrm{m} / \mathrm{d}$ \\
\hline & ticks & & $\mathrm{m}$ & $\mathrm{m} / \mathrm{d}$ & $d / b d$ & $\mathrm{~m}$ & $m$ & $\mathrm{~m}$ & $d / h x d$ & $d$ & $\mathrm{~m}$ & & \\
\hline
\end{tabular}

positive influence no influence negative influence $m=$ small
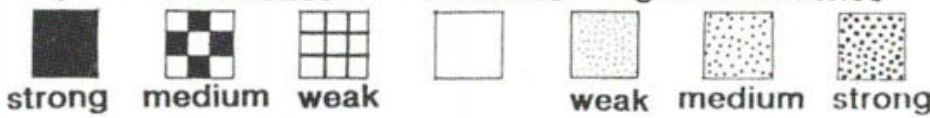

$\mathrm{d}=$ big
bd $=$ very big

Fig. 1. The effect of different vegetation bioclimates on human health during the summer period 

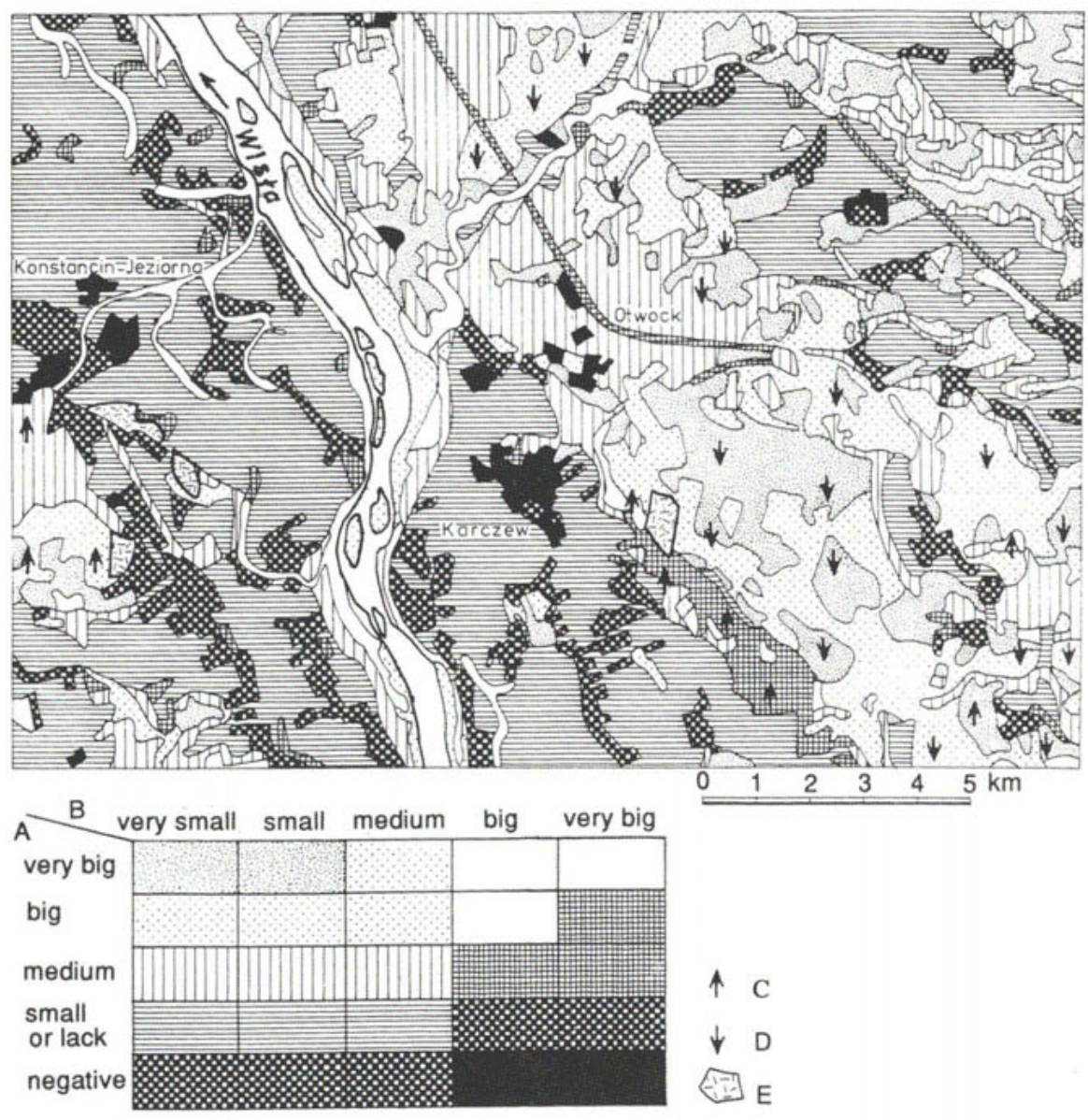

Fig. 2. Recreational usefulness of regions in Warsaw district

tion, contents of ozone, phytoaerosoles and aeroplancton in the air etc.), the established recreational bioclimate is relatively durable throughout the whole vegetation period and can be changed only under the influence of very strong airing and intensive anthropogenic pollution exceeding the limits of self-clcaning abilities.

3. Each vegetational type affects human organism in a different way, and this influence can be either strong or weak, positive or negative. There are ecological systems of universal influence (positive or negative irrespective of health condition and age of persons resting), and discriminatory (positive for persons having one type of illness, and negative for those having another type). Fig.1 illustrates the influence of man's residence in a given environment on some chosen attributes of organism (expressed in terms used in pharmacology). It shows, for cx- 
ample, that there are types of vegetation opposed in this respect (for example, pine woods on the one hand and oak-hornbeam on the other). It permits an arrangement of recreational traffic in such a way as to get maximum benefit from natural values of environment as a medical treatment factor.

4. Taking into account the applied criteria of typology and classification of ecological systems which have their source in a homogenous composition of species, the results obtained from research of the particular model areas can be transferred to larger areas using the maps of real vegetation. This permits an assessment of a recreational usefulness of larger regions (see Fig. 2). On this map two elements were taken into consideration: the impact of recreational bioclimate on health (A) and degree of threat from plant pollens, parasites and onerous insects (B). Besides, the arrows mark ecological systems of soothing action lowering arterial blood pressure (D), and of stimulating action increasing pressure (C). Moreover, the map shows isolated nature reserves (E) to be protected against excessive and chaotic tourist traffic.

5. The analysis of the area under investigation from the viewpoint of its aesthetic and emotional impact has shown that it varies according to the phenological period. The same structure can be evaluated in a different way, according to the season of the year, time of the day, as well as age and health condition of the person making an assessment. It appears that the role of the somatic factor is by far greater than it is generally held. Of much stronger aesthetic and emotional influence are abutments of two or more formations (for example, of forest and meadow or forest, meadow and water etc.) than the interior of the given formation.

\section{REFERENCES}

Douglas W.R., 1975, Forest Recreation, McMillan Publ., New York.

For s te r C.A., D a vis H., 1984, Forests and Public Health, Bibl. Medica Ltd., Nottingham.

Grodzins kij A.M., 1989, Fitoergonomika, Naukova Dumka, Kijev.

Kurasin W.J., 1988, Viedienije khoziajstva v rekreacjonnykh lesakg, Agropromizdat, Moskva.

S mith W.H., 1981, Air Pollution and Forest Interactions between Air Contaminants and Forest Ecosystems, Springer Inc., New York.

We h m e r C.N., 1929-1935, Die Pflanzenstoffe 1-3, G. Fischer Verl. Jena. 
